\title{
"Impact of Covid-19 on SME portfolios in Morocco: Evaluation of banking risk costs and the effectiveness of state support measures"
}

\begin{tabular}{|c|c|}
\hline AUTHORS & $\begin{array}{l}\text { Mohamed Habachi (iD) } \\
\text { Salim El Haddad }\end{array}$ \\
\hline ARTICLE INFO & $\begin{array}{l}\text { Mohamed Habachi and Salim El Haddad (2021). Impact of Covid-19 on SME } \\
\text { portfolios in Morocco: Evaluation of banking risk costs and the effectiveness of } \\
\text { state support measures. Investment Management and Financial Innovations, } \\
\text { 18(3), 260-276. doi:10.21511/imfi.18(3).2021.23 }\end{array}$ \\
\hline DOI & http://dx.doi.org/10.21511/imfi.18(3).2021.23 \\
\hline RELEASED ON & Thursday, 09 September 2021 \\
\hline RECEIVED ON & Tuesday, 03 August 2021 \\
\hline ACCEPTED ON & Thursday, 02 September 2021 \\
\hline LICENSE & $\begin{array}{l}(c) \overline{\mathrm{EY}} \\
\text { This work is licensed under a Creative Commons Attribution } 4.0 \text { International } \\
\text { License }\end{array}$ \\
\hline JOURNAL & "Investment Management and Financial Innovations" \\
\hline ISSN PRINT & $1810-4967$ \\
\hline ISSN ONLINE & $1812-9358$ \\
\hline PUBLISHER & LLC "Consulting Publishing Company "Business Perspectives" \\
\hline FOUNDER & LLC "Consulting Publishing Company "Business Perspectives" \\
\hline
\end{tabular}

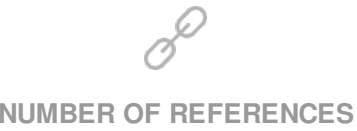

33
NUMBER OF FIGURES

2
NUMBER OF TABLES

16

(C) The author(s) 2021. This publication is an open access article. 


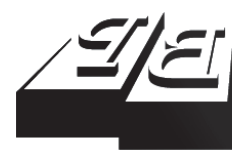

\section{BUSINESS PERSPECTIVES}

(2)

Hryhorii Skovoroda lane, 10,

Sumy, 40022, Ukraine
LLC "CPC "Business Perspectives"

www.businessperspectives.org
Received on: $3^{\text {rd }}$ of August, 2021 Accepted on: $2^{\text {nd }}$ of September, 2021 Published on: $9^{\text {th }}$ of September, 2021

(C) Mohamed Habachi, Salim El Haddad, 2021
Mohamed Habachi (Morocco), Salim El Haddad (Morocco)

IMPACT OF COVID-19 ON SME
PORTFOLIOS IN MOROCCO:
EVALUATION OF BANKING RISK
COSTS AND THE EFFECTIVENESS
OF STATE SUPPORT MEASURES

\section{Abstract}

This study proposed a method for constructing rating tools using logistic regression and linear discriminant analysis to determine the risk profile of SME portfolios. The objective, firstly, is to evaluate the impact of the crisis due to the Covid-19 by readjusting the profile of each company by using the expert opinion and, secondly, to evaluate the efficiency of the measures taken by the Moroccan state to support the companies during the period of the pandemic.

The analysis in this paper showed that the performance of the logistic regression and linear discriminant analysis models is almost equivalent based on the ROC curve. However, it was revealed that the logistic regression model minimizes the risk cost represented in this study by the expected loss. For the support measures adopted by the Moroccan government, the study showed that the failure rate (critical situation) of the firms benefiting from the support is largely lower than that of the non-beneficiaries.
Keywords

JEL Classification probability of default, expert opinion, expected loss, internal rating

C51, G21, G32

\section{INTRODUCTION}

Mohamed Habachi, Ph.D., Professor, Department of management sciences, Faculty of Legal, Economic and Social Sciences, Agdal, University MED 5, Morocco. (Corresponding author)

Salim El Haddad, Ph.D. Student, Department of management sciences, Faculty of Legal, Economic and Social Sciences, Agdal, University MED 5, Morocco.

This is an Open Access article, distributed under the terms of the Creative Commons Attribution 4.0 International license, which permits unrestricted re-use, distribution, and reproduction in any medium, provided the original work is properly cited.

Conflict of interest statement: Author(s) reported no conflict of interest
The Covid-19 gave rise to a cessation of activity in several economic sectors, which generated a wave of company failures, increasing the rate of default. The intervention of the public power to safeguard employment and guarantee the continuity of activities helped to minimize the risk and reduce the failure of companies.

In this context, rating models designed on the basis of data from a normal economic environment give biased results because the probability of default $(P D)$ calculated by the model does not correspond to the reality imposed by the crisis. This imposes the readjustment of the risk profile of the portfolio by using different techniques such as the Bayesian approach or the expert's opinion.

This paper proposes a Malus system that allows readjusting the risk profile of the portfolio by taking into account the $P D$ conditioned by the intervention of the public power.

To determine the impact of the crisis and to evaluate the effectiveness of state intervention, this paper studied the downgrading of the rating of a portfolio composed of small and medium-sized enterprises of a bank in Morroco and the variation of the provision for expected loss $(E L)$ provided for in the accounting standard IFRS 9. 
The calculation of $E L$, according to the IRB -foundation approach, is based on three components: $P D$, Loss Given Default $(L G D)$ and Exposure At Default $(E A D)$. Therefore, this paper presents the construction of two rating grids using logistic regression $(L R)$ and linear discriminant analysis $(L D A)$. This allows, firstly, to evaluate the impact of the modeling on the determination of the portfolio risk profile and consequently on the expected loss, and, secondly, to evaluate the effectiveness of the state intervention.

The paper consists of the literature review, the methodology, empirical results, discussion, and conclusion.

\section{LITERATURE REVIEW AND HYPOTHESES}

This paper defines the approach to the construction of rating tools and the determination of the empirical probability of default by class by two techniques which are the $L R$ and $L D A$.

The use of linear discriminant analysis for solvency modeling goes back to the 1960s with the research of Altmane (1967). The use of this technique has later attracted the interest of several researchers such as Deakin (1972). It continues to be of interest to researchers such as Habachi et al. (2019) who combined the $L D A$ and expert opinion, and Svabova et al. (2020) who combined $L R$ and $L D A$ to determine models of failure prediction for SMPs.

As far as logistic regression is concerned, the first studies were started in the 1980s. However, this is still the most common technique for modeling the default. Indeed, several recent studies have addressed this area such as Madar (2014), Benbachir and Habachi (2018), and Zizi et al. (2020).

The explanation of the failure is made by variables specific to each company. They can be quantitative, qualitative, or macroeconomic variables. The qualitative variables have been studied by Courdec and Renault (2005), Grunert et al. (2005), Yildirak and Suer (2013), and Habachi et al. (2019). Figlewski et al. (2012) studied the impact of macroeconomic factors on firm default.

In addition, several researchers have compared modeling approaches to determine the best performing models such as Altman et al. (1994), who compared linear discriminant analysis and neural networks, Worth and Cronin (2003), who compared linear discriminant analysis and logistic regression in the health domain, and Pavlyshenko (2016), who studied learning machines and linear and the Bayesian logistic regression for failure prediction.

Credit rating has been studied by Figini and Giudici (2011), Moon et al. (2011), Ubarhande et al. (2021), Chai et al. (2019), and Chi et al. (2020). While the Covid-19 impact on business failure has been studied by Gourinchas et al. (2020).

The provisioning of $E L$ by banks represents a risk cost that impacts the relationship between banks and companies, particularly SMEs. This impact has been studied by Bushman (2016), Novotny-Farkas (2016), Vaněk and Hampel (2017), Benbachir and Habachi (2018), Cohen and Edwards (2017), and Engelmann et al. (2020).

Measuring the performance of models is a major concern for researchers. This study uses the ROC curve. Indeed, the ROC curve has been studied by several researchers to evaluate the performance of prediction models such as Bradley (1997) for the evaluation of machine learning algorithms, Satchel and Xia (2008), who applied the use of the curve in the evaluation of scoring, and Engelmann et al. (2003), who used the ROC curve to evaluate the discriminative power of scoring systems.

The objective of this study is to compare the linear discriminant analysis ( $L D A)$ and the logistic regression $(L R)$, and then to evaluate the Covid-19 impact and the intervention of the state to support the companies. For this purpose, this study formulates the following hypotheses:

H1: The modelling techniques have an impact on the cost of risk (expected loss).

H2: The state support has a positive impact on beneficiary companies. 


\section{METHODOLOGY}

Credit risk is defined as the probability that a borrower will not meet its obligations in accordance with the contractual terms. This probability is determined for a one-year horizon.

A counterparty is considered to be in default if these receivables are reclassified as distressed, particularly if there is the persistence of unpaid payments for a period exceeding 90 days, three unpaid installments, a significant decrease in sales, reclassification of the case as a contentious claim, chronic overage of authorizations, expired authorizations not renewed for a period exceeding 90 days, and account freeze (account with no activity for a period exceeding 180 days).

The Basel Committee defines two types of Internal Rating Based (IRB) approach, namely: the IRB -foundation, which requires the institutions to estimate only the $P D$, the other components which are $(L G D),(E A D)$ and maturity $(M)$ are given by the Basel II or by the central bank of each country, and the $I R B$-advanced approach, which requires the institutions to estimate all parameters $(P D, L G D, E A D$ and $M)$ by its own internal models.

Under IFRS 9, the expected loss is covered by provisions and must be accounted for. The same orientation has been adopted by the Basel Committee (Bank for International Settlements, 2015).

In the $I R B$-foundation, determination of the $P D$ is the most important component. This section presents the methodology adopted to model the $P D$ by $L R$ approach and $L D A$ approach and to construct the rating tools related to them, then the approach used to readjust the portfolio by the expert opinion and finally to determine the $E L$.

The variables $\left(X_{j}\right), j=1, . ., 12$ used in this study are defined as follows:

- $\quad X_{1}$ : Total sales for the year 2019 .

- $X_{2}$ : The number of persons employed in the company.
- $X_{3}$ : The number of years the company has been in business.

- $X_{4}: \mathrm{ROE}$ is defined as the ratio of net income to equity.

- $X_{5}$ : The financial costs are defined as the ratio between the financial costs and $X_{1}$.

$X_{6}$ : The debt ratio is defined as the ratio of medium and long-term debt to equity.

- $X_{7}$ : The proportion of current assets financed by equity is defined as the ratio of the remaining equity after financing fixed assets divided by current assets.

- $X_{8}$ : The capital structure is defined as the ratio of equity to total liabilities.

$X_{9}$ : The turnover of fixed assets and requirement working capital (current assets -current liabilities) is defined by the ratio between $X_{1}$ and the sum of fixed assets and requirement working capital.

- $X_{10}$ : Macroeconomic information obtained from the central bank, i.e. the rate of failure in the sector of activity of the company.

- $X_{11}$ : Seniority of the main manager in the company and the sector (chairman or general director).

- $X_{12}$ : Legal form of the company.

\subsection{Logistic regression}

The correlation between a firm's default and each variable $X_{i}$ of that firm $(i)$ is determined by the univariate analysis. Univariate and multivariate logistic regression models that link default $Y$ and the variables $\left(X_{i}\right), i=1, . ., 12$ are written as:

$$
Y_{i}=\frac{e^{\beta_{0}+\beta_{1} \times x_{i}}}{1+e^{\beta_{0}+\beta_{1} \times x_{i}}} \text { et } Y_{i}=\frac{e^{\beta_{0}+\sum_{i=1}^{12} \beta_{i} \times x_{i}}}{1+e^{\beta_{0}+\sum_{i=1}^{12} \beta_{i} \times x_{i}}} \text {. }
$$

The estimation of the parameters is made by the maximum likelihood method available by software such as SPSS and XL-STAT. 
The validity of the model is verified by the Wald test. The null hypothesis $H_{0}$ is $H_{0}: \beta_{1}=0$ (for multivariate analysis is $\left.H_{0}: \beta_{i}=0\right)$ ). The statistic test is:

$$
\begin{aligned}
& S_{1}=\frac{\hat{\beta}_{1}^{2}}{\hat{\sigma}_{\hat{\beta}_{1}}^{2}} \times \\
& \times\left(S_{i}=\frac{\hat{\beta}_{i}^{2}}{\hat{\sigma}_{\hat{\beta}_{i}}^{2}} \text { for multivariate analysis }\right) .
\end{aligned}
$$

Under $H_{0}, \quad S_{1}$ is a $\chi_{1}^{2} . \quad H_{0}$ is rejected if $S_{1}>$ inv. $\chi_{1}^{2}(0.05)$.

The model adopted can predict the classification of companies. However, two situations must be distinguished:

1. The firms are classified by the model in their current class. Healthy firms are considered to be "true healthy" and firms in default are considered to be "true default". $N$ is the number of good classified companies.

2. The firms that are not classified by the model in their current class. For healthy firms classified as defaults, they are considered "false default", while those in default classified as healthy are considered "false healthy".

The classification matrix A is defined by:

$$
A=\left[\begin{array}{cc}
\text { Truehealty } & \text { falsehealthy } \\
\text { falsedefault } & \text { truedefault }
\end{array}\right] .
$$

$N$ is the number of correctly classified enterprises. It is the sum of the diagonal of the matrix $(A)$.

The ratio of classification capacity noted $(R C C)$ is:

$$
\begin{aligned}
& \frac{N}{n}=(\text { True healty }+ \text { true default }) /(\text { True healty }+ \\
& + \text { true default }+ \text { false default }+ \text { false healthy })
\end{aligned}
$$

The comparison of models is made based on the highest ROC curve. Habachi et al. (2019) gave the conditions of acceptability of the model. Indeed, a model with a ROC curve higher than $70 \%$ is acceptable.
The explanatory variables to be retained are determined by univariate analysis between the default and each variable. In fact, only the variables whose $R O C$ curve is greater than 0.60 are retained.

The validate the multivariate model is made by the following tests, whose hypothesis formulation, statistical tests, and decision rules (the Wald test, the likelihood ratio test, and the Hosmer-Lemeshow test) are presented in Appendix A.

\subsection{Linear discriminant analysis (LDA)}

The firms must be classified by the discriminate function into two classes "healthy" and "default". In 1936, Fisher (1936) proposed a score function that predicts the classification in the two classes. This function, also called score function, is defined as:

$$
\begin{aligned}
& F(X)=K X^{T}+k_{0}=k_{0}+ \\
& +k_{1} X_{1}+k_{2} X_{2}+\ldots+k_{12} X_{12} .
\end{aligned}
$$

With

- $\quad K=\left(k_{1}, k_{2}, \ldots, k_{12}\right)$ the vector of discrimination coefficients and $k_{0}$ a constant.

- $\quad X=\left(X_{1}, X_{2}, \ldots, X_{12}\right)$ the vector of discriminant variables.

Let $c$ be the separation point, a firm is considered healthy if $F(X)>c$.

Each class (default $Y=0$ and healthy $Y=1$ ) has a distinct discrimination function. The determination of discrimination functions is available in several software packages such as SPSS and XL-STAT.

The univariate analysis allows determining the discriminating variables. Indeed, a variable is discriminant if the means of the group is equal. The null hypothesis $H_{0}$ says that "equality of group means.". The statistical test is defined by the Fisher's Ratio. The decision rule is to reject $H_{0}$ if $p$-value is less than $5 \%$.

The significance of the coefficients is verified by three tests, namely the Box's $M$ test (test of equali- 
ty of variance-covariance matrices of groups), the Wilks' Lambda test, and the $\boldsymbol{Q}_{\text {press }}$ test (model performance test).

The functions at group centroids allow calculating the mean of scores of each group:

- $\quad m_{1}$ the number of enterprises in the class of enterprises in default $(Y=0)$;

- $\quad m_{2}$ the number of enterprises in the class of healthy enterprises $(Y=1)$;

- $\quad a$ the mean of the scores of the class of enterprises in default $(Y=0)$ by function discriminant for $Y=1$;

- $\quad b$ the mean of the scores of the class of healthy enterprises $(Y=1)$ by function discriminant for $Y=1$.

The optimal separation point $(O P S)$ is defined by:

$$
O P S=\frac{m_{1} a+m_{2} b}{m_{1}+m_{2}} .
$$

If $m_{1}=m_{2}$, then $O P S=\frac{a+b}{2}$.

\subsection{The rating models}

Based on the score function, this study defines two rating tools consisting of the following classes:

- Class 1: class of companies with an excellent financial position and very low default risk. The score is high and exceeds 86 .

- Class 2: class of companies with a very good financial situation and very good quality characters. The score is high and exceeds 76 .

- Class 3: class of companies with a good financial situation and good quality characters. The score is high and exceeds 65 .

- Class 4: class of companies with a relatively good financial situation and good quality characters. The score is high and exceeds 55 .
- Class 5: class of companies with a medium financial situation and relatively good quality characters. The score is high and exceeds 46 .

- Class 6: class of companies with a medium financial situation and medium quality characters. The score is high and exceeds 40 .

- Class 7: class of companies with a critical financial situation. The score is high and exceeds 30 .

- Class 8: class of companies with a very critical financial situation. The score is lower than 30 .

The rating score of the company $(i)$ noted $R S_{i}$ is defined by:

$$
R S_{i}=\frac{S_{i}}{\operatorname{Max}(S)} \cdot 100
$$

where $S_{i}$ is the score assigned to the company $(i)$ by the classification function.

For each class $C$, the $P D$ of the firms in that class noted $\left(P D_{C}\right)$, is equal to the $P D$ of firm $(i)$ knowing that firm $(i)$ belongs to class $C$, i.e.

$$
P D_{C}=P\left(Y_{i}=0 / i \in \text { classe } C\right) \text {. }
$$

The probability of default per class is defined as the ratio of the number of defaulting firms in the class to the total number of firms in that class.

\subsection{Impact of Covid-19 adjustment of the portfolio risk profile}

The impact of the Covid-19 crisis has far exceeded the recession generated by the 2008 financial crisis. Indeed, the consequences of this crisis are very important for the real and financial economy, whose first effects have affected the secondary and tertiary sectors and the financial markets.

In Morocco, the crisis is particularly penalizing the activities of very small and medium enterprises. According to a first survey carried out by the $\mathrm{HCP}^{1}$ in April 2020 among enterprises, the production units temporarily or permanently out of the business of VSE and SME represent respectively $72 \%$ and $26 \%$ of enterprises in each category.

1 High commissioner of planning, Kingdom of Morocco. 
In this context, the Moroccan state has focused its policy on two pillars, namely solidarity and the dynamism of the banking sector. For the first pillar, the crisis plan is based on the establishment of the Covid-19 fund, which has made it possible to mobilize the necessary funds to finance containment, economic recovery, the vaccination campaign, etc. For the second pillar, the policy adopted is based on the establishment of a guarantee fund managed by the $C G C$ 2 with the objective of maintaining jobs and activity through the distribution of "Oxygen" credit, followed by an action aimed at the relaunching of the economy through the distribution of "Relaunch" credit. The banking action within this framework had an objective of approximately 80 million MAD destined to finance 140,000 eligible companies.

The use of statistical data for the construction of the rating tool is made on the basis of data concerning the 2019 financial year because the data concerning 2020 are impacted by the crisis. This situation leads to a gap between the rating assigned by the rating tool and the real profile of the rated companies.

To correct this gap, this study readjusted the rating model using expert opinion to define a malus system that takes into account the state support and the classification of companies into two classes: "healthy" and "critical" conditional on the state support. Therefore, in the function of the recourse to state support and the company's situation, the rating of the company will be readjusted using the following malus: - Healthy situation without state support:
Maintaining the class.

- Healthy situation with state support: Degradation of a single class.

- Critical situation without state support: Degradation of two classes.

- Critical situation with state support: Degradation of three classes or default.

\subsection{The cost of risk}

This study evaluates the cost of risk by the expected loss (EL) defined by the multiplication of the three components of credit risk, namely $P D$, $E A D$, and $L G D$. This is the average loss associated with a credit at each date of its term.

Let $A$ be the amount authorized by the credit line, recorded off-balance sheet. Under the $I R B$ - foundation approach, the $P D$ is determined by the internal rating model (this study uses two tools), the loss given default represents $45 \%$ of the exposure in case of default and the $E A D$ is defined in function of the amount accounted for in the balance sheet $\left(M_{O}\right)$, the authorization of the credit line $(A)$ and the credit conversion factor $(C C F)$ :

$$
\left\{\begin{array}{c}
E A D=M_{O}+F C C \cdot M_{1} \\
M_{1}=A-M_{O}
\end{array}\right.
$$

With $M_{1}$ : Current value in the balance in the balance sheet. $F C C$ : is equal to $75 \%$ (BCBS, 2006, IRB - foundation).

\section{RESULTS}

\subsection{The database}

The sample used is composed of 721 small and medium-sized enterprises in Morocco. Healthy enterprises represent $92.51 \%$ (667 enterprises) and failing enterprises represent $7.49 \%$ (54 enterprises).

\subsection{Univariate analysis by logistic regression}

The results of the Wald test and the discriminant power of each variable are presented in Table B1 (Appendix B). The univariate analysis shows that $X_{1}, X_{3}, X_{6}, X_{7}$ do not have significant discriminating power because the area under the $R O C$ curve is below 0.55 . However, this study uses the variables that increase the discriminating power of the model.

2 Central guarantee fund, Kingdom of Morocco. 
Therefore, the discriminant pow- Therefore, the discriminant power is calculated to the significant variables er is calculated to the significant variables $\left(X_{2}, X_{4}, X_{5}, X_{8}, X_{9}, X_{10}, X_{11}, X_{12}\right)$ represent- $\left(X_{2}, X_{4}, X_{5}, X_{8}, X_{10}, X_{11}\right)$ representing an iniing an initial model $M_{1}$ adding progressively the variables not significant $\left(X_{1}, X_{3}, X_{6}, X_{7}\right)$.

The discriminant power of the model shows that $X_{7}$ is the only variable that does not participate in the evolution of the discriminant power of the model (Table B2, Appendix B). Therefore, the variable $X_{7}$ is eliminated.

The rest of this study concerning $L R$ uses the variables $\mathrm{V}_{j}^{\prime}, 1 \leq j \leq 11$ with:

$$
\begin{aligned}
& V=\left(V_{1}^{\prime}, V_{2}^{\prime}, \mathrm{V}_{3}^{\prime}, \ldots, \mathrm{V}_{11}^{\prime}\right)= \\
& =\left(X_{1}, X_{2}, X_{3}, X_{4}, X_{5}, X_{6}, X_{8}, X_{9}, X_{10}, X_{11}, X_{12}\right) .
\end{aligned}
$$

\subsection{Univariate analysis by linear discriminant analysis}

The results of the equality means of group test are presented in Table B3 (Appendix B). The univariate analysis shows that $X_{1}, X_{3}, X_{6}, X_{7}, X_{9}$, $X_{12}$ do not have significant discriminating power because the $p$-value is higher than 0.05 . However, this study uses the variables that increase the discriminating power of the model.

tial model $M_{1}$ by adding progressively the variables not significant $\left(X_{1}, X_{3}, X_{6}, X_{7}, X_{9}, X_{12}\right)$.

The discriminant power of the model shows that $X_{1}$ and $X_{7}$ are variables that do not participate in the evolution of the discriminant power of the model (Table B4, Appendix B). Therefore, the variables $X_{1}$ and $X_{7}$ are eliminated.

The rest of this study concerning linear discriminant analysis uses the variables $T_{j}, 1 \leq j \leq 10$ with:

$$
\begin{aligned}
& T=\left(T_{1}, T_{6}, \ldots, T_{10}\right)= \\
& =\left(X_{2}, X_{3}, X_{4}, X_{5}, X_{6}, X_{8}, X_{9}, X_{10}, X_{11}, X_{12}\right) .
\end{aligned}
$$

\subsection{Multivariate logistic regression}

The estimation of $\beta=\left(\beta_{0}, \beta_{1}, \ldots, \beta_{p}\right)$ and Wald test are given in Table B5 (Appendix B). Indeed, the $H_{0}: \beta_{i}=0$ is rejected. Consequently, the $\beta_{i}$ are individually significant.

The results of the test of likelihood ratio reject the $H_{0}$ because the statistical test is equal to 86.206 , which is equivalent to the $p$-value less than 0.05 . Consequently, the $\beta_{i}$ are significant.

$A \cup C=0.789$

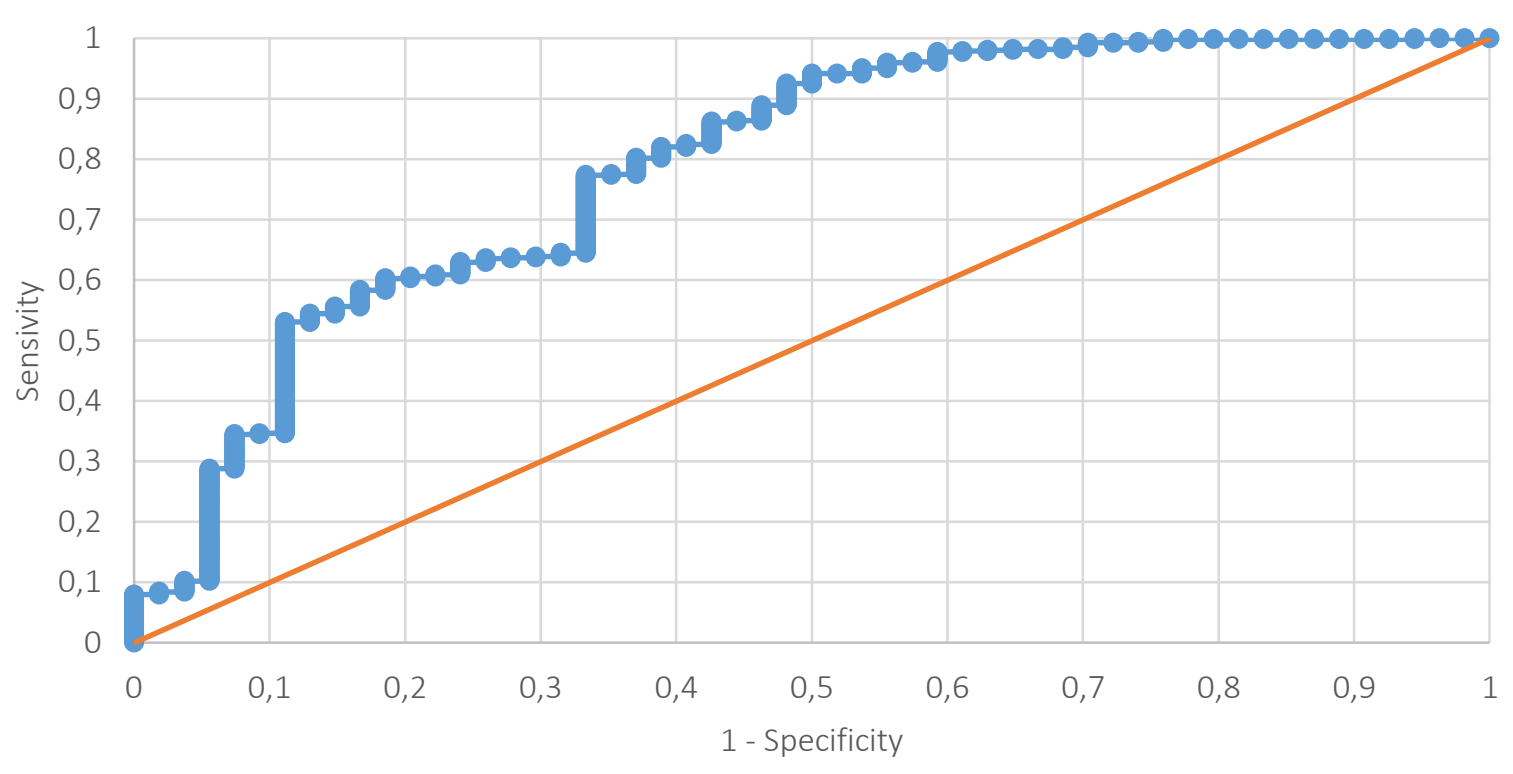

Figure 1. Discriminatory power $R L(R O C)$ 
The results of the Hosmer-Lemeshow test show the $p$-value equal to 0.08 . Consequently, the $H_{0}$ : "the model is correct" is accepted.

In terms of discriminatory power, the model is acceptable because the $R O C$ curve is equal to $78.9 \%$.

The estimation of the parameters allows determining the score function. Indeed, the $S_{1}(i)$ of each company $(i)$ is defined by:

$$
\begin{aligned}
& S_{1}(i)=-5.597-0.002 \cdot \mathrm{V}_{i, 1}^{\prime}-0.005 \cdot \mathrm{V}_{i, 2}^{\prime}+ \\
& +0.007 \cdot \mathrm{V}_{i, 3}^{\prime}+0.012 \cdot \mathrm{V}_{i, 4}^{\prime}+0.008 \cdot \mathrm{V}_{i, 5}^{\prime}- \\
& -0.002 \cdot \mathrm{V}_{i, 6}^{\prime}+0.002 \cdot \mathrm{V}_{i, 7}^{\prime}-0.005 \mathrm{~V}_{i, 8}^{\prime}+ \\
& +0.007 \cdot \mathrm{V}_{i, 9}^{\prime}+0.078 \cdot \mathrm{V}_{i, 10}^{\prime}+0.023 \cdot \mathrm{V}_{i, 11}^{\prime}
\end{aligned}
$$

\subsection{Linear discriminant analysis and the classification function}

The discriminant analysis yields two score functions respectively for defaulting companies $(Y=0)$ and healthy companies $(Y=1)$. To develop the rating tool, this study uses the score function for healthy companies $(Y=1)$ defined by:

$$
\begin{aligned}
& F_{1}(T)=-106+0.03 \cdot T_{1}+0.1 \cdot T_{2}+ \\
& +0.03 \cdot T_{3}-0.03 \cdot T_{4}-0.02 \cdot T_{5}+0.06 \cdot T_{6}+ \\
& +0.04 \cdot T_{7}+0.06 \cdot T_{8}+0.73 \cdot T_{9}+1.88 \cdot T_{10} .
\end{aligned}
$$

The results of Box's $\mathrm{M}$ test, shows that $H_{0}$ can be rejected because the $p$-value is lower than 0.05 (Table B6, Appendix B).

Table B7 (Appendix B) shows that the Wilks' Lambda test rejects $H_{0}$ because the $p$-value is lower than 0.05 .

Table B8 (Appendix B) shows that $(R C C)$ is equal to $93.3 \%$ that is equivalent to a very satisfactory correct classification of companies.

The $Q_{\text {presse }}$ test rejected $H_{0}$ because the statistical test $Q_{\text {presse }}$ is equal to 541.78 and is superior to $3.84\left(\operatorname{Inv} \cdot \chi_{1}^{2}(0.05)\right)$.

In terms of discriminatory power, the model is acceptable because the $R O C$ curve is equal to $78.2 \%$.

Table B9 (Appendix B) presents the mean of scores per class. The optimal separation point is:

$$
O S P=\frac{54 \cdot(-1.618)+667 \cdot 0.131}{721} \sim 0 .
$$

\subsection{The rating grid}

The distribution of the companies in the sample and $P D$ per class is presented in Table 1.

\section{$A \cup C=0.782$}

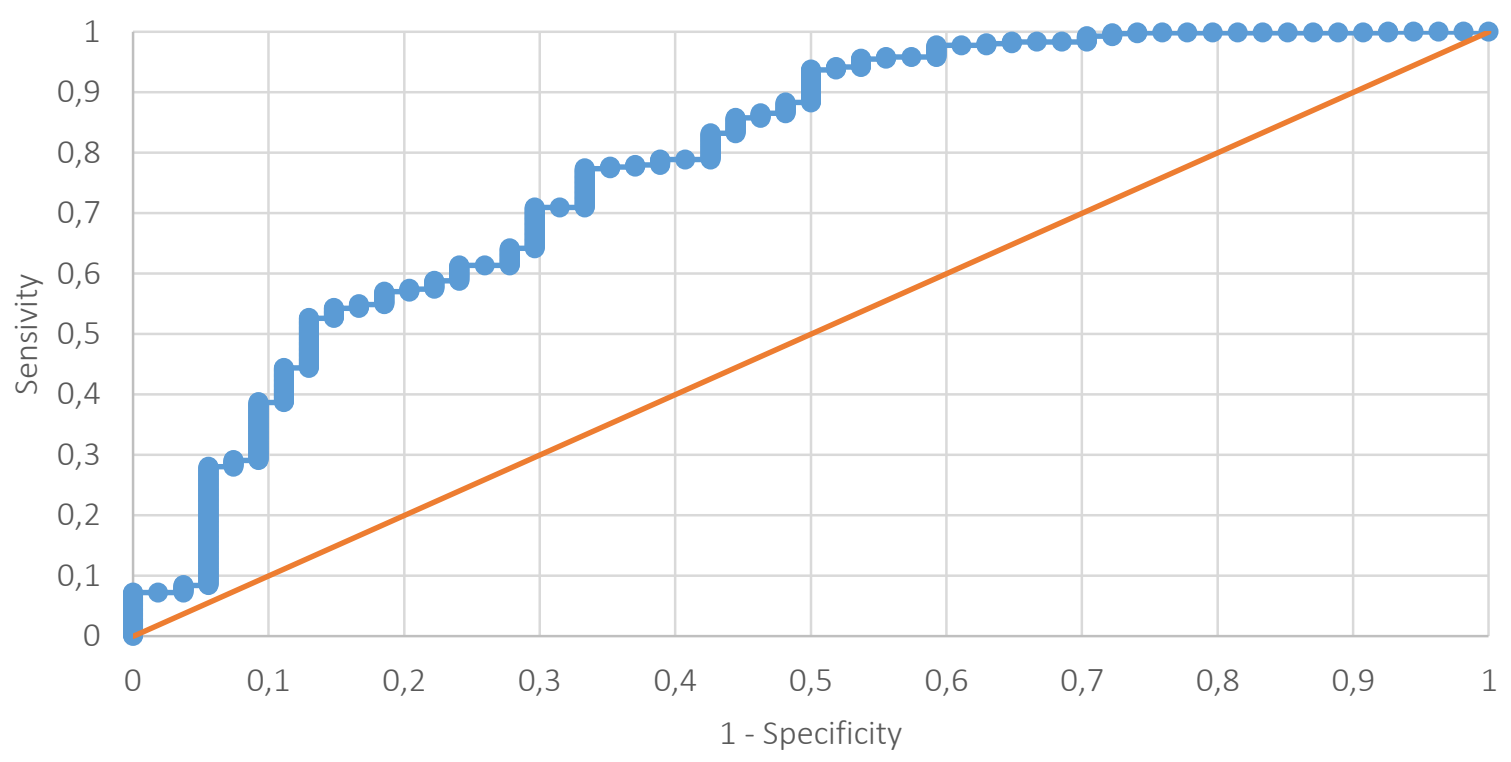

Figure 2. Discriminatory power $L D A(R O C)$ 
Table 1. The $P D$ per class of two models

\begin{tabular}{|c|c|c|c|c|c|c|}
\hline \multirow{2}{*}{ Class } & \multicolumn{3}{|c|}{ LR Model } & \multicolumn{3}{|c|}{$A D L$ Model } \\
\hline & PTF healthy & PTF in default & PD & PTF healthy & PTF in default & PD \\
\hline 1 & 11 & 0 & $0.0 \%$ & 4 & 0 & $0.00 \%$ \\
\hline 2 & 120 & 2 & $1.6 \%$ & 92 & 2 & $2.13 \%$ \\
\hline 3 & 223 & 13 & $3.0 \%$ & 238 & 7 & $2.86 \%$ \\
\hline 4 & 163 & 15 & $5.8 \%$ & 174 & 10 & $5.43 \%$ \\
\hline 5 & 79 & 12 & $8.1 \%$ & 107 & 7 & $6.14 \%$ \\
\hline 6 & 32 & 5 & $13.5 \%$ & 38 & 5 & $11.63 \%$ \\
\hline 7 & 28 & 3 & $22.2 \%$ & 9 & 8 & $47.06 \%$ \\
\hline 8 & 11 & 4 & $57.7 \%$ & 5 & 15 & $75.00 \%$ \\
\hline Total & 667 & 54 & & 667 & 54 & \\
\hline
\end{tabular}

The portfolio adjustment is based on expert opinion. The experts associated with this study are the credit portfolio managers who manage the sample of companies used. Expert opinion determines which companies have benefited from state support and which have not by class and classifies them as healthy or critical companies which allow determining the downgrading of the companies in the different rating classes.

The classification of companies according to state support and their solvency is given in Table 2.

The number of companies benefiting from state support is equal to 565 which represents $84.7 \%$ of the portfolio. Among these companies, 503 are considered healthy, which represents $89 \%$ of the portfolio supported by the state. The latter covers several sectors such as trade which represents 50.09\% (283) private educational institution which represents $11.15 \%$ (63), Buildings and public works which represents $9.56 \%$ (54) tour- ism $7.79 \%$ (44), services $11.50 \%$ (65) and others with $9.91 \%$ (56).

The rate of critical enterprises that benefited from state support is $12.32 \%$, which is much lower than the rate of critical enterprises that did not benefit from state support, which is $75.86 \%$. This means that the state action has cushioned the rate of defiance due to the Covid-19 crisis.

This assessment is confirmed for classes 6,7 , and 8 by the fact that the criticality rate for companies that have benefited from state support is $29.57 \%$ whereas it is $100 \%$ for companies that have not benefited from state support.

The downgrading of the companies in the different rating classes by each model is presented in Tables 3 and 4 .

The portfolio adjustment resulted in 32 companies being classified as default.

Table 2. Classification according to state support

\begin{tabular}{|c|c|c|c|c|c|c|c|c|c|c|}
\hline \multirow{3}{*}{ Class } & \multicolumn{5}{|c|}{ LR Model } & \multicolumn{5}{|c|}{ LDA Model } \\
\hline & \multirow{2}{*}{ number } & \multicolumn{2}{|c|}{ with state support } & \multicolumn{2}{|c|}{ without state support } & \multirow{2}{*}{ number } & \multicolumn{2}{|c|}{ with state support } & \multicolumn{2}{|c|}{ without state suppor } \\
\hline & & Healthy & Critical & Healthy & Critical & & Healthy & Critical & Healthy & Critical \\
\hline 1 & 11 & 4 & 0 & 5 & 2 & 4 & 1 & 0 & 2 & 1 \\
\hline 2 & 120 & 80 & 13 & 20 & 7 & 92 & 60 & 5 & 20 & 7 \\
\hline 3 & 223 & 182 & 11 & 21 & 9 & 238 & 188 & 25 & 16 & 9 \\
\hline 4 & 163 & 135 & 10 & 10 & 8 & 174 & 144 & 12 & 10 & 8 \\
\hline 5 & 79 & 63 & 7 & 2 & 7 & 107 & 80 & 7 & 10 & 10 \\
\hline 6 & 32 & 25 & 4 & 0 & 3 & 38 & 26 & 8 & 0 & 4 \\
\hline 7 & 28 & 11 & 15 & 0 & 2 & 9 & 4 & 3 & 0 & 2 \\
\hline 8 & 11 & 3 & 2 & 0 & 6 & 5 & 0 & 2 & 0 & 3 \\
\hline Total & 667 & 503 & 62 & 58 & 44 & 667 & 503 & 62 & 58 & 44 \\
\hline
\end{tabular}


Table 3. $L R$ Model - Adjustment of the portfolio

\begin{tabular}{|c|c|c|c|c|c|c|c|c|c|c|}
\hline \multirow{2}{*}{ Class } & \multirow{2}{*}{ Initial portfolio } & \multicolumn{9}{|c|}{ Downgrading of the portfolio } \\
\hline & & 1 & 2 & 3 & 4 & 5 & 6 & 7 & 8 & DEF \\
\hline 1 & 11 & 5 & 4 & 2 & & & & & & \\
\hline 2 & 120 & & 20 & 80 & 7 & 13 & & & & \\
\hline 3 & 223 & & & 21 & 182 & 9 & 11 & & & \\
\hline 4 & 163 & & & & 10 & 135 & 8 & 10 & & \\
\hline 5 & 79 & & & & & 2 & 63 & 7 & 7 & \\
\hline 6 & 32 & & & & & & & 25 & 3 & 4 \\
\hline 7 & 28 & & & & & & & & 11 & 17 \\
\hline 8 & 11 & & & & & & & & & 11 \\
\hline Adjusted portfolio & 667 & 5 & 24 & 103 & 199 & 159 & 82 & 42 & 21 & 32 \\
\hline
\end{tabular}

Table 4. LDA model - Adjustment of the portfolio

\begin{tabular}{|c|c|c|c|c|c|c|c|c|c|c|}
\hline \multirow{2}{*}{ Class } & \multirow{2}{*}{ Initial portfolio } & \multicolumn{9}{|c|}{ Downgrading of the portfolio } \\
\hline & & 1 & 2 & 3 & 4 & 5 & 6 & 7 & 8 & DEF \\
\hline 1 & 4 & 2 & 1 & 1 & & & & & & \\
\hline 2 & 92 & & 20 & 60 & 7 & 5 & & & & \\
\hline 3 & 238 & & & 16 & 188 & 9 & 25 & & & \\
\hline 4 & 174 & & & & 10 & 144 & 8 & 12 & & \\
\hline 5 & 107 & & & & & 10 & 80 & 10 & 7 & \\
\hline 6 & 38 & & & & & & & 26 & 4 & 8 \\
\hline 7 & 9 & & & & & & & & & 9 \\
\hline 8 & 5 & & & & & & & & & 5 \\
\hline Adjusted portfolio & 667 & 2 & 21 & 77 & 205 & 168 & 113 & 48 & 11 & 22 \\
\hline
\end{tabular}

The portfolio adjustment resulted in 22 companies being classified as default.

\subsection{The cost of risk}

The portfolio studied represents a total use of outstanding credit $\left(M_{O}\right)$ equal to $4,685.40$ million MAD for a funding commitment $\left(A=M_{O}+M_{1}\right)$ equal to 5,157 million MAD. The distribution of outstanding amounts and commitments by rating class is preseted in Table B10 (Appendix B).

Table 5. $L R$ model - the EL per class (million MAD)
Knowing that the $C C F$ is $75 \%$, the $L G D$ is $45 \%$ and that the $P D$ per class is given in Table 1, the total expected loss ( $E L)$ by class per logistic regression model is presented in Table 5 .

Table 5 shows that it is necessary to make a provision for the debts of companies reclassified as defaults, i.e. 501.79 million MAD, as well as the expected loss.

The EL by class per LDA model is presented in Table 6.

\begin{tabular}{|c|c|c|c|c|c|c|c|c|}
\hline \multirow{2}{*}{ Class } & \multicolumn{4}{|c|}{ Initial portfolio } & \multicolumn{4}{|c|}{ Adjusted portfolio } \\
\hline & $M_{0}$ & $M_{1}$ & EAD & EL & $M_{0}$ & $M_{1}$ & EAD & EL \\
\hline 1 & 50.6 & 13.55 & 47.2125 & 0.01 & 23 & 19.6 & 21.46 & 0.00 \\
\hline 2 & 407.75 & 28.24 & 400.69 & 2.88 & 86.35 & 29.5 & 83.94 & 0.60 \\
\hline 3 & 968.1 & 103.18 & 942.30 & 12.72 & 372.19 & 99.8 & 364.44 & 4.92 \\
\hline 4 & 1708.51 & 114.54 & 1679.87 & 43.84 & 918.71 & 119.65 & 895.48 & 23.37 \\
\hline 5 & 1104.62 & 198.47 & 1055.01 & 38.45 & 1526.23 & 199.35 & 1499.45 & 54.66 \\
\hline 6 & 312.51 & 8.9 & 310.28 & 18.85 & 1012.5 & 9.2 & 970.25 & 58.94 \\
\hline 7 & 362.02 & 4.53 & 360.89 & 36.05 & 446.84 & 4.5 & 438.94 & 43.85 \\
\hline 8 & 242.89 & 0.19 & 242.84 & 63.05 & 269.39 & -10 & 264.34 & 68.64 \\
\hline Total & 5157 & & 5039.10 & 215.87 & 4655.21 & & 4538.32 & 254.98 \\
\hline
\end{tabular}


Table 6. $L D A$ model - the $E L$ per class (million MAD)

\begin{tabular}{|c|c|c|c|c|c|c|c|c|}
\hline \multirow{2}{*}{ Class } & \multicolumn{4}{|c|}{ Initial portfolio } & \multicolumn{4}{|c|}{ Adjusted portfolio } \\
\hline & $\mathrm{M}_{0}$ & $\mathrm{M}_{1}$ & EAD & EL & $\mathrm{M}_{0}$ & $M_{1}$ & EAD & EL \\
\hline 1 & 28.4 & 19.6 & 43.10 & 0.00 & 14.20 & 9.8 & 21.55 & 0.00 \\
\hline 2 & 378.5 & 29.5 & 400.63 & 3.84 & 89.38 & 11.32 & 97.87 & 0.94 \\
\hline 3 & 862.2 & 99.8 & 937.05 & 12.06 & 311.91 & 30.85 & 335.05 & 4.31 \\
\hline 4 & 1588.35 & 119.65 & 1678.09 & 41.00 & 801.15 & 87.95 & 867.11 & 21.19 \\
\hline 5 & 918.65 & 199.35 & 1068.16 & 29.51 & 1453.53 & 123.03 & 1545.80 & 42.71 \\
\hline 6 & 299.8 & 9.2 & 306.70 & 16.05 & 850.44 & 165.03 & 974.21 & 50.99 \\
\hline 7 & 356.5 & 4.5 & 359.88 & 76.21 & 400.52 & 33.18 & 425.41 & 90.09 \\
\hline 8 & 253 & -10 & 245.50 & 82.86 & 91.66 & 14.01 & 102.17 & 34.48 \\
\hline Total & 4685.40 & 471.6 & 5039.10 & 261.54 & 4012.78 & 475.17 & 4369.17 & 244.70 \\
\hline
\end{tabular}

Table 6 shows that it is necessary to make a provision for the debts of companies reclassified as defaults, i.e. 672.62 million MAD, as well as the expected loss.

\subsection{Comparison of two models}

The discriminating power shows a small difference of $0.7 \%$ between the two models. Indeed, the $R O C$ curve of the logistic regression and linear discriminant analysis models are respectively $78.9 \%$ and $78.2 \%$.

As regards the $E L$, the logistic regression model generates a lower expected loss (215.87 million MAD) than that generated by the linear discriminant analysis model (261.54 million MAD). The variation is $21.32 \%$.

After readjusting the risk profile of the portfolio, the provision increased as it covers the expected loss and the defaulted debts. Indeed, it reached 756.77 million MAD for the logistic regression model against 917.32 million MAD for the linear discriminant analysis, i.e. a variation of $21.22 \%$.

The Covid-19 crisis has led to a catastrophic increase in provisions. Indeed, they are $250.56 \%$ and $250.73 \%$ respectively for the $L R$ and the $L D A$ models.

\section{DISCUSSION}

The use of expert opinion showed that the risk profile of the portfolio had deteriorated significantly due to the Covid-19 crisis. Tables 4 and 5 show that the readjustment of the portfolio resulted in the reclassification of high-risk businesses to default.

Table 3 shows that the use by banks of the financing possibilities guaranteed by the state for economic stimulation has made it possible to reduce the rate of company failures since the rate of companies in a critical situation that have benefited from state support is lower than that of companies that have not benefited from state support.

Before adjustment, the model based on logistic regression is relatively better than the one based on linear discriminant analysis with a small difference of about $0.7 \%$. Despite this small difference, the two models generate a totally different expected loss since the model based on linear discriminant analysis generates a $21.32 \%$ higher expected loss.

After readjustment, the global provision increased by $250 \%$. However, the model based on linear discriminant analysis generates an aggregate provision that is $21.22 \%$ higher than the logistic regression.

\section{CONCLUSION}

This study examines two hypotheses, namely the impact of modeling on the cost of risk under IFRS 9 and the effectiveness of the measures taken by the state for economic recovery. For both hypotheses, this study constructs two rating tools using two techniques, which are logistic regression and linear discriminant analysis. 
The statistical models determined by logistic regression and linear discriminant analysis combine two types of variables which are the quantitative variables from the accounting documents and the qualitative variables concerning the customer. These models cannot capture the Covid-19 crisis impact. For this purpose, this study uses expert opinion to readjust the ratings and the probability of default assigned to each counterparty by the initial models. The approach used is simple but can be developed by further studies by refining the approach used or by using the Bayesian analysis.

This study shows empirically that modeling has a significant impact on the level of provisioning of the expected loss even if the performance of the models used is almost equivalent, which may generate an opportunity for arbitrage depending on the level of losses. On the other hand, it shows that the measures taken by the state prevented a mass failure of the companies studied.

\section{AUTHOR CONTRIBUTIONS}

Conceptualization: Mohamed Habachi, Salim El Haddad.

Data curation: Mohamed Habachi, Salim El Haddad.

Formal analysis: Mohamed Habachi, Salim El Haddad.

Funding acquisition: Mohamed Habachi, Salim El Haddad.

Investigation: Mohamed Habachi, Salim El Haddad.

Methodology: Mohamed Habachi, Salim El Haddad.

Project administration: Mohamed Habachi.

Resources: Mohamed Habachi, Salim El Haddad.

Software: Mohamed Habachi, Salim El Haddad.

Supervision: Mohamed Habachi.

Validation: Mohamed Habachi, Salim El Haddad.

Visualization: Mohamed Habachi, Salim El Haddad.

Writing - original draft: Mohamed Habachi, Salim El Haddad.

Writing - review \& editing: Mohamed Habachi.

\section{REFERENCES}

1. Altman, E. I. (1968). Financial ratios, discriminant analysis and the prediction of corporate bankruptcy. Journal of Finance, 23(4), 589-609. https://doi. org/10.2307/2978933

2. Altman, G., Marco, F., \& Varetto, F. (1994). Corporate Distress Diagnosis: Comparisons using Linear Discriminant Analysis and Neural Networks (the Italian experience). Journal of Banking and Finance, 18, 505-529. https://doi. org/10.1016/0378-4266(94)90007-8

3. Bank for International Settlements. (2005). International convergence of capital measurement and capital standards. Basel, Switzerland. Retrieved from https://www.bis.org/ publ/bcbs118.pdf

4. Bank for International Settlements. (2015). Guidance on credit risk and accounting for expected credit losses. Basel, Switzerland. Retrieved from https://www.bis.org/bcbs/publ/ d350.pdf

5. Benbachir, S., \& Habachi, M. (2018). Assessing the Impact of Modelling on the Expected Credit Loss (ECL) of a Portfolio of Small and Medium-sized Enterprises. Universal Journal of Management, 6(10), 409-431. https://doi. org/10.13189/ujm.2018.061005

6. Bradley, A. P. (1997). The use of the area under the ROC curve in the evaluation of machine learning algorithms. Pattern Recognition, 30(7), 1145-1159. https://doi.org/10.1016/S00313203(96)00142-2

7. Transparency, accounting discretion, and bank stability. Economic Policy Review, Issue Aug, 129-149.
8. Chai, N., Wu, B., Yang, W., \& Shi, B. (2019). A multicriteria approach for modeling small enterprise credit rating: Evidence from China. Emerging Markets Finance and Trade, 55(11), 25232543. https://doi.org/10.1080/1540 496X.2019.1577237

9. Chi, G., Yu, S., \& Zhou, Y. (2020). A novel credit evaluation model based on the maximum discrimination of evaluation results. Emerging Markets Finance and Trade, 56(11), 2543-2562. https://doi.org/10.1080/154049 6X.2019.1643717

10. Cohen, B., \& Edwards, Jr G. (2017). The new era of expected credit loss provisioning. BIS Quarterly Review, 36-59. Retrieved from https://www.bis.org/publ/ qtrpdf/r_qt1703f.pdf 
11. Courdec, F., \& Renault, O. (2005). Times-to-default: life cycle, global and industry cycle impacts (Research Paper No. 142). FAME-International Center of Financial Asset Management and Engineering. Retrieved from https://www.researchgate.net/ publication/5021538_Times-ToDefaultLife_Cycle_Global_and_ Industry_Cycle_Impact

12. Deakin, E. B. (1972). A discriminant analysis of predictors of business failure. Journal of Accounting Research, 10(1), 167-179. https:// doi.org/10.2307/2490225

13. Engelmann, B., Hayden, E., \& Tasche, D. (2003). Measuring the Discriminative Power of Rating Systems (Discussion Paper No. 2003, 01). Bundesbank. Retrieved from https://ssrn.com/ abstract $=2793951$

14. Engelmann, B., \& Pham, $H$. (2020). Measuring the Performance of Bank Loans under Basel II/III and IFRS 9/CECL. Risks, 8(3), 93. https://doi.org/10.3390/ risks 8030093

15. Figini, S., \& Giudici, P. (2011). Statistical merging of rating models. Journal of the Operational Research Society, 62(6), 1067-1074. https:// doi.org/10.1057/jors.2010.41

16. Figlewski, S., Frydman, H., \& Liang, W. (2012). Modeling the effect of macroeconomic factors on corporate default and credit rating transitions. International Review of Economics and Finance, 21(1), 87-105. https://doi.org/10.1016/j. iref.2011.05.004

17. Fisher, R., (1936). The use of multiple measurements in taxonomic problems. Annals of Eugenics, 7, 179-188.

18. Gourinchas, P.-O., Kalemli-Özcan, S., Penciakova, V., \& Sander, N. (2020). COVID-19 and SME Failures (Working Paper No. 27877). National Bureau of Economic Research. Retrieved from http://www. nber.org/papers/w27877.pdf

19. Grunert, J., Norden, L., \& Weber, M. (2005). The role of nonfinancial factors in internal credit ratings. Journal of Banking \& Fi- nance, 29(2), 509-531. https://doi. org/10.1016/j.jbankfin.2004.05.017

20. Habachi, M., Benbachir, S., \& McMillan, D. (rev.ed.). (2019). Combination of linear discriminant analysis and expert opinion for the construction of credit rating models: The case of SMEs. Cogent Business \& Management, 6(1), 1685926. https://doi.org/10.1 080/23311975.2019.1685926

21. Hosmer, D. W., \& Lemeshow, S. (1980). Goodness-of-fit test for the multiple logistic regression model. Communications in Statistics, 9(10), 1043-1069. http://doi. org/10.1080/03610928008827941

22. Hosmer, D., Lemeshow, S., \& Sturdivant, R. (2013). Applied Logistic Regression (3 ${ }^{\text {rd }}$ ed.). New York: John Wiley \& Sons.

23. Madar, L. (2014). Scoring rendszerek hatásai a gazdasági tőkeszámitás során alkalmazott portfóliómodellek eredményeire [The effects of scoring systems on the results of portfolio models used in economic capital calculations] ( $\mathrm{PhD}$ thesis). University of Kaposvár.

24. Moon, T. H., Kim, Y., \& Sohn, S. Y. (2011). Technology credit rating system for funding SMEs. Journal of the Operational Research Society, 62(4), 608-615. https://doi. org/10.1057/jors.2010.15

25. Novotny-Farkas, Z. (2016). The interaction of the IFRS 9 expected loss approach with supervisory rules and implications for financial stability. Accounting in Europe, 13(2), 197-227. https://doi.org/10.1 080/17449480.2016.1210180

26. Pavlyshenko, B. (2016). Machine learning, linear and Bayesian models for logistic regression in failure detection problems. IEEE International Conference on Big Data, 2046-2050. Retrieved from https://arxiv.org/ftp/arxiv/papers/1612/1612.05740.pdf

27. Satchel, S., \& Xia, W. (2008). 8-Analytic models of the ROC Curve: Applications to credit rating model validation. The Analytics of Risk Model Validation, Quantitative Finance, 113-133.
https://doi.org/10.1016/B978075068158-2.50011-1

28. Svabova, L., Michalkova, L., Durica, M., \& Nica, E. (2020). Business Failure Prediction for Slovak Small and Medium-Sized Companies. Sustainability, 12(11), 4572. https://doi.org/10.3390/ su12114572

29. Ubarhande, P., Chandani, A., \& McMillan, D. (rev.ed.). (2021). Elements of Credit Rating: A Hybrid Review and Future Research Agenda. Cogent Business \& Management, 8(1), 1878977. https:// doi.org/10.1080/23311975.2021.1 878977

30. Vaněk, T., \& Hampel, D.(2017). The probability of default under IFRS9: Multi-period estimation and macroeconomic forecast. Acta Universitatis Agriculturae et Silviculturae Mendelianae Brunensis, 65(2), 759-776. http://doi.org/10.11118/actaun201765020759

31. Worth, A., \& Cronin, M. (2003). The use of discriminant analysis, logistic regression and classification tree analysis in the development of classification models for human health effects. Journal of Molecular Structure: THEOCHEM, 622, 97-111. Retrieved from https://publications.jrc.ec.europa. eu/repository/handle/JRC21426

32. Yildirak, K., \& Suer, O. (2013). Qualitative determinants and credit-default risk: evidence from Turkey. Aktualni problemy ekonomiky - Actual problems of economics, 7(145), 333-344. Retrieved from https://www.researchgate. net/publication/259584233_Qualitative_Determinants_and_CreditDefault_Risk_Evidence_from_ Turkey

33. Zizi, Y., Oudgou, M., \& El Moudden, A. (2020). Determinants and Predictors of SMEs' Financial Failure: A Logistic Regression Approach. Risks, 8(4), 107. https:// doi.org/10.3390/risks8040107 


\section{APPENDIX A}

\section{The Likelihood ratio test}

The likelihood ratio test is presented as follows:

$$
\left\{\begin{array}{l}
H_{0}: \operatorname{logit}(P(Y=1))=\beta_{0} \\
H_{1}: \operatorname{logit}(P(Y=1))=\beta Z^{\prime}
\end{array} .\right.
$$

The statistic of test is defined by:

$$
L R=-2\left[\frac{\sum_{i=1}^{n} \ln \left(\frac{1}{1+e^{\beta_{0}}}\right)+y_{i} \beta_{0}}{\sum_{i=1}^{n} \ln \left(\frac{1}{1+e^{\beta Z}}\right)+y_{i} \beta Z^{\prime}}\right]=-2\left[\frac{L L\left(M_{1}\right)}{L L\left(M_{2}\right)}\right] .
$$

$L R$ is $\chi_{n}^{2}$. If $L R>i n v \cdot \chi_{n}^{2}(0,05), H_{0}$ is rejected.

\section{Hosmer-Lemeshow test}

The objective of this test is defined by Hosmer and Lemeshow (1980), and Hosmer et al. (2013). The null hypothesis $H_{0}$ says that "the model is correct". The test statistic, $(H L)$, is defined by:

$H L=\sum_{g=1}^{10} \frac{\left(O_{g}-E_{g}\right)^{2}}{E_{g}}$.

$H L$ is $\chi_{8}^{2}$. If $L R>i n v \cdot \chi_{8}^{2}(0,05), H_{0}$ is rejected.

The Box's M test (test of equality of variance-covariance matrices of groups)

Let a sample of size $(n)$ be divided into two groups of size $n_{1}$ and $n_{2}$. The $H_{0}$ says that "the groups' covariance matrices are all equal". Let $S_{i}$ be the covariance of the variables in the group $(i)$. The statistical test is:

$M=\left(\left(n_{1}+n_{2}\right)-2\right) \ln \left(\left|\frac{\sum_{i=1}^{2}\left(n_{i}-1\right) S_{i}}{(n-2)}\right|\right)-\sum_{i=1}^{2}\left(n_{i}-2\right) \ln \left(\left|S_{i}\right|\right)$.

$M$ is $\chi^{2}$ with $D D L=l=\frac{\text { number of variable } \cdot(\text { numbre of variable }+1)}{2}$.

$H_{0}$ is rejected if $\mathrm{M}$ is superior to inv. $\chi_{l}^{2}(0.05)$.

\section{The Wilks' Lambda test}

Wilks' Lambda is used to test the equality of group means The null hypothesis $H_{0}$ says that "equality of group means". 
For the binary case, lambda is $F_{p, n-p-1}$ whid $p$ is number of variables. $H_{0}$ is rejected if Wilks' Lambda is superior to inv. $F_{10,710}(0.05)$

\section{The $Q_{\text {press }}$ test}

The $\boldsymbol{Q}_{\text {press }}$ test presented in Habachi et al. (2019). $H_{0}$ says that "the equality of the number of individuals correctly classified by the discriminating function and by hazard". The statistical test is:

$$
Q_{\text {presse }}=\frac{(n-(2 \cdot N))^{2}}{n} \text {. }
$$

with: $n$ is the sample size, $N$ is the number of correctly classified enterprises.

$Q_{\text {presse }}$ is a $\left(\chi_{1}^{2}\right) \cdot H_{0} Q_{\text {presse }}>i n v \cdot \chi_{1}^{2}(0.05)$.

\section{APPENDIX B}

Table B1. Logistic regression of univariate analysis

\begin{tabular}{|c|c|c|c|c|}
\hline Variable & DDL & Khi (Wald) & $P=\operatorname{Pr}(x>$ Wald $)$ & AUC \\
\hline$x_{1}$ & & 0.014 & 0.904 & $54.1 \%$ \\
\hline$x_{2}$ & 1 & 5.950 & 0.015 & $59.9 \%$ \\
\hline$x_{3}$ & 1 & 0.000 & 0.988 & $51.1 \%$ \\
\hline$x_{4}$ & 1 & 11.458 & 0.001 & $62.6 \%$ \\
\hline$x_{5}$ & 1 & 7.660 & 0.006 & $60.6 \%$ \\
\hline$x_{6}$ & 1 & 0.477 & 0.490 & $53 \%$ \\
\hline$x_{7}$ & 1 & 0.017 & 0.897 & $53.4 \%$ \\
\hline$x_{8}$ & 1 & 3.573 & 0.059 & $59.2 \%$ \\
\hline$x_{9}$ & 1 & 1.121 & 0.290 & $56.5 \%$ \\
\hline$X_{10}$ & 1 & 5.189 & 0.023 & $59.8 \%$ \\
\hline$x_{11}$ & 1 & 66.832 & $<0.0001$ & $73.8 \%$ \\
\hline$x_{12}$ & 1 & 2.682 & 0.101 & $56.6 \%$ \\
\hline
\end{tabular}

Table B2. Discriminative power of models as a function of variables

\begin{tabular}{c|c|c|c|c|c}
\hline Model & $M_{1}$ & $M_{2}=M_{1}+X_{1}$ & $M_{3}=M_{2}+X_{3}$ & $M_{4}=M_{3}+X_{6}$ & $M_{5}=M_{4}+X_{7}$ \\
\hline AUC & $78 \%$ & $78.2 \%$ & $78.8 \%$ & $78.9 \%$ & $78.8 \%$ \\
\hline
\end{tabular}

Table B3. Linear discriminant analysis of univariate analysis

\begin{tabular}{|c|c|c|c|c|c|}
\hline Variable & Lambda & $\mathbf{F}$ & $D D L 1$ & $D D L 2$ & $p$-value \\
\hline$x_{1}$ & 1.000 & 0.014 & 1 & 719 & 0.904 \\
\hline$x_{2}$ & 0.991 & 6.208 & 1 & 719 & 0.013 \\
\hline$x_{3}$ & 1.000 & 0.000 & 1 & 719 & 0.988 \\
\hline$x_{4}$ & 0.984 & 11.930 & 1 & 719 & 0.001 \\
\hline$x_{5}$ & 0.989 & 8.099 & 1 & 719 & 0.005 \\
\hline$x_{6}$ & 0.999 & 0.477 & 1 & 719 & 0.490 \\
\hline$x_{7}$ & 1.000 & 0.017 & 1 & 719 & 0.897 \\
\hline$x_{8}$ & 0.995 & 3.616 & 1 & 719 & 0.050 \\
\hline$x_{9}$ & 0.998 & 1.126 & 1 & 719 & 0.289 \\
\hline$x_{10}$ & 0.993 & 5.338 & 1 & 719 & 0.021 \\
\hline$X_{11}$ & 0.849 & 128.050 & 1 & 719 & $<0.0001$ \\
\hline$x_{12}$ & 0.996 & 2.989 & 1 & 719 & 0.084 \\
\hline
\end{tabular}


Table B4. Discriminative power of models as a function of variables

\begin{tabular}{c|c|c|c|c|c|c|c}
\hline Model & $M_{1}$ & $\begin{array}{c}M_{2} \\
\left(M_{1}+X_{12}\right)\end{array}$ & $\begin{array}{c}M_{3} \\
\left(M_{2}+X_{9}\right)\end{array}$ & $\begin{array}{c}M_{4} \\
\left(M_{3}+X_{6}\right)\end{array}$ & $\begin{array}{c}M_{5} \\
\left(M_{4}+X_{7}\right)\end{array}$ & $\begin{array}{c}M_{6} \\
\left(M_{4}+X_{1}\right)\end{array}$ & $\begin{array}{c}M_{7} \\
\left(M_{4}+X_{3}\right)\end{array}$ \\
\hline AUC & $76.7 \%$ & $77 \%$ & $77.7 \%$ & $77.8 \%$ & $77.5 \%$ & $77.6 \%$ & $78.2 \%$ \\
\hline
\end{tabular}

Table B5. Parameter estimation and Wald test

\begin{tabular}{|c|c|c|c|c|}
\hline \multirow{2}{*}{ Constant } & $\beta_{i}$ & Standard deviation & $\mathrm{Khi}^{2}$ ( Wald) & $p v=P(x>$ Wald $)$ \\
\hline & $B_{0}=-5.597$ & 1.604 & 12.183 & 0.000 \\
\hline$x_{1}$ & $B_{1}=-0.002$ & 0.011 & 0.033 & 0.855 \\
\hline$x_{2}$ & $B_{2}=-0.005$ & 0.005 & 1.003 & 0.317 \\
\hline$x_{3}$ & $B_{3}=0.007$ & 0.005 & 1.851 & 0.174 \\
\hline$x_{4}$ & $B_{4}=0.012$ & 0.006 & 3.697 & 0.054 \\
\hline$x_{5}$ & $B_{5}=0.008$ & 0.005 & 3.078 & 0.079 \\
\hline$x_{6}$ & $B_{6}=-0.002$ & 0.005 & 0.202 & 0.653 \\
\hline$x_{7}$ & $B_{7}=0.002$ & 0.007 & 0.126 & 0.722 \\
\hline$x_{8}$ & $B_{8}=-0.005$ & 0.006 & 0.744 & 0.388 \\
\hline$x_{9}$ & $B_{9}=0.007$ & 0.004 & 2.295 & 0.130 \\
\hline$x_{10}$ & $B_{10}=0.078$ & 0.011 & 54.254 & $<0.0001$ \\
\hline$x_{11}$ & $b_{11}=0.023$ & 0.017 & 1.760 & 0.185 \\
\hline$x_{12}$ & - & - & - & - \\
\hline
\end{tabular}

Table B6. Box's M test

\begin{tabular}{c|c|c|c|c}
\hline$-2 \log (M)$ & $\chi_{55}^{2}$ (Observed value) & $\chi_{55}^{2}$ (Critical value) & $\boldsymbol{p}$-value & $\alpha$ \\
\hline 230.79 & 3.912 & 1.33 & $<0.0001$ & 0.05 \\
\hline
\end{tabular}

Table B7. Wilks' Lambda test

\begin{tabular}{c|c|c|c|c}
\hline Lambda & $\boldsymbol{F}_{\mathbf{1 0 , 7 1 0}}$ (observed value) & $\boldsymbol{F}_{\mathbf{1 0 , 7 1 0}}$ (critical value) & $\boldsymbol{p}$-value & alpha \\
\hline 0.825 & 15.088 & 1.844 & $<0.0001$ & 0.05 \\
\hline
\end{tabular}

Table B8. The matrix of classification gap

\begin{tabular}{|c|c|c|c|}
\hline \multirow{2}{*}{ Current Class } & \multicolumn{2}{|c|}{ Predicted class } & \multirow{2}{*}{ Total } \\
\hline & Default $(Y=0)$ & Healthy $(Y=1)$ & \\
\hline Default $(Y=0)$ & 22 & 32 & 54 \\
\hline Healthy $(Y=1)$ & 16 & 651 & 667 \\
\hline Default $(Y=0)(\%)$ & $3.05 \%$ & $4.44 \%$ & $100 \%$ \\
\hline Healthy $(Y=1)(\%)$ & $2.22 \%$ & $90.29 \%$ & $100 \%$ \\
\hline
\end{tabular}

Table B9. The mean of scores per class

\begin{tabular}{c|cc}
\hline Group & The mean of the scores by function discriminant for $Y=1$ \\
\hline 0 & -1.618 \\
\hline 1 & 0.131 \\
\hline
\end{tabular}


Table B10. The distribution of $M_{0}$ and $\left(M_{0}+M_{1}\right)$ per rating class (million MAD)

\begin{tabular}{|c|c|c|c|c|}
\hline \multirow{2}{*}{ Rating class } & \multicolumn{2}{|c|}{ LR Model } & \multicolumn{2}{|c|}{ LDA Model } \\
\hline & $M_{0}$ & $M_{0}+M_{1}$ & $M_{0}$ & $M_{0}+M_{1}$ \\
\hline 1 & 37.05 & 50.6 & 28.4 & 48 \\
\hline 2 & 379.51 & 407.75 & 378.5 & 408 \\
\hline 3 & 864.92 & 968.1 & 862.2 & 962 \\
\hline 4 & 1593.97 & 1708.51 & 1588.35 & 1708 \\
\hline 5 & 906.15 & 1104.62 & 918.65 & 1118 \\
\hline 6 & 303.61 & 312.51 & 299.8 & 309 \\
\hline 7 & 357.49 & 362.02 & 356.5 & 361 \\
\hline 8 & 242.7 & 242.89 & 253 & 243 \\
\hline Total & 4685.40 & 5157 & 4685.40 & 5157 \\
\hline
\end{tabular}

